\title{
Nanoquasicrystalline $\mathrm{Al}-\mathrm{Fe}-\mathrm{Cr}-\mathrm{Ti}$ alloy matrix $/ \gamma-\mathrm{Al}_{2} \mathrm{O}_{3}$ nanocomposite powders: The effect of the ball milling process
}

\author{
W. Xu ${ }^{\mathrm{a}, *}$, M. Galano ${ }^{\mathrm{a}}$ and F. Audebert ${ }^{\mathrm{a}, \mathrm{b}, \mathrm{c}}$ \\ ${ }^{a}$ Department of Materials, University of Oxford, 16 Parks Road, OX1 3PH, Oxford, United Kingdom \\ ${ }^{\mathrm{b}}$ Advanced Materials Group, INTECIN (UBA - CONICET), Facultad de Ingeniería, Universidad de Buenos \\ Aires, Paseo Colón 850, Ciudad de Buenos Aires, 1063, Argentina \\ ${ }^{\mathrm{c}}$ Department of Mechanical Engineering and Mathematical Sciences, Oxford Brookes University, Wheatley \\ Campus, OX33 1HX, Oxford, United Kingdom \\ * Corresponding author
}

\begin{abstract}
Quasicrystalline aluminium alloys and aluminium based nanocomposites with the advantage of high strength over commercial aluminium alloys have been studied for many years. In this work a nanoquasicrystalline Al-Fe-Cr-Ti alloy powder and a nanocomposite consisting of a mixture of a nanoquasicrystalline alloy and nanosize $\gamma-\mathrm{Al}_{2} \mathrm{O}_{3}$ powders were produced through mechanical milling with different milling speeds. It has been observed that a higher milling time or milling speed can improve the homogeneity of the $\gamma-\mathrm{Al}_{2} \mathrm{O}_{3}$ distribution. The $\alpha-\mathrm{Al}$ crystallite size decreases and the hardness increases with the milling time. The smallest crystallite size $(14 \mathrm{~nm})$ and the highest hardness value $\left(638 \mathrm{HV}_{10 \mathrm{~g}}\right)$ were obtained for the nanocomposite after 30 hours of milling at $250 \mathrm{rpm}$. As the $\alpha$-Al crystallite size is the main change in the microstructure during the ball milling process, the change in the hardness of the milled powders was found to follow a Hall-Petch type relation with an exponent of 0.25 .
\end{abstract}

Key words: Mechanical milling, aluminium, quasicrystals, nanocomposites, hardness

\section{Introduction}

Compared with conventional alloys, composites have the advantages of high strength and high stiffness [1]. Decreasing the reinforcement particle size to nanoscale helps improving both the mechanical strength and the ductility. Kang et al. [2] illustrated that $\mathrm{Al} / 1 \mathrm{vol} \% \mathrm{Al}_{2} \mathrm{O}_{3}(50 \mathrm{~nm})$ nanocomposite had almost the same tensile strength with the $\mathrm{Al} / 10 \mathrm{vol} \% \mathrm{SiC}(13 \mu \mathrm{m})$ composite and much higher ductility. Knowles et al. [3] processed Al6061/SiC nanocomposites through mechanical milling and hot isostatic pressing. With 12.9 vol\% of $\mathrm{SiC}$ addition, the composites they processed increased the yield strength from $131 \mathrm{MPa}$ to $229 \mathrm{MPa}$. The $\mathrm{SiC}$ has normally inert chemical behaviour with the matrix, but some authors reported that the $\mathrm{SiC}$ could react with $\mathrm{Al}$, generating $\mathrm{Al}_{4} \mathrm{C}_{3}$ intermetallics and $\mathrm{Al}-\mathrm{Si}$ eutectic, leading to undesired behaviour [4, 
5]. Compared with the $\mathrm{SiC}, \mathrm{Al}_{2} \mathrm{O}_{3}$ is widely used in aluminium based nanocomposites because it is chemically inert with Al [6]. Alumina is one of the most important structural materials with several transition phases that have enormous technological and industrial significance [7]. The $\gamma$-phase in particular is one of the polymorphic phases of alumina with numerous applications [7]. The $\gamma$-phase, with a cubic cell and a Fd-3m symmetry is a metastable phase and intrinsically nanocrystalline in nature that can also be easily synthesized by a variety of methods $[8,9] \cdot \gamma-\mathrm{Al}_{2} \mathrm{O}_{3}$ can be transformed into the stable $\alpha-\mathrm{Al}_{2} \mathrm{O}_{3}$ under heat treatment with a transformation sequence at high temperature $\left(750^{\circ} \mathrm{C}-1200^{\circ} \mathrm{C}\right)[10]$. The hardness of the $\gamma$ $\mathrm{Al}_{2} \mathrm{O}_{3}$ synthetized by different methods has been measured by several authors with values of 714 to $744 \mathrm{Kg} / \mathrm{mm}^{2}$ [11-13].

Mazaheri et al. [14] fabricated an $\mathrm{Al} 356 / \alpha-\mathrm{Al}_{2} \mathrm{O}_{3}$ composite through mechanical milling. The hardness they measured through nanoindentation increases from $75 \mathrm{~kg} / \mathrm{mm}^{2}$ to $216 \mathrm{~kg} / \mathrm{mm}^{2}$ with 20 vol. $\%$ of $\alpha-\mathrm{Al}_{2} \mathrm{O}_{3}$ addition. This represents an increase in the hardness of $9.4 \%$ per $\%$ of the $\alpha-\mathrm{Al}_{2} \mathrm{O}_{2}$ reinforcement, which is higher than the increase of $7.5 \%$ per $\%$ of $\mathrm{SiC}$ reinforcement obtained by Knowles et al [3]. Therefore, the use of nanosize $\gamma-\mathrm{Al}_{2} \mathrm{O}_{2}$ as reinforcement in Al-based composites is very promising is the nanoparticles' clusters can be broken-up and the nanoparticles are homogenously distributed in the Al alloy matrix.

Nanostructured Al-based alloys with a microstructure composed of nanoquasicrystalline particles embedded in an Al matrix, are well studied and known in the literature as "nanoquasicrystalline Al alloys" [15-22]. These alloys are normally produced by rapid solidification (melt-spinning or gas atomization) containing icosahedral quasicrystalline particles with typically size under $500 \mathrm{~nm}$. Inoue et al. [18] found 45 vol.\% of icosahedral particles for the $\mathrm{Al}_{93} \mathrm{Fe}_{3} \mathrm{Cr}_{2} \mathrm{Ti}_{2}$ (at.\%) alloy atomized powder, and Audebert et al. [19] found $\sim 2$ vol.\% of icosahedral particles for the melt-spun $\mathrm{Al}_{93} \mathrm{Fe}_{3} \mathrm{Cr}_{2} \mathrm{Ti}_{2}$ (at.\%) alloy. Nanoquasicrystalline Al alloys are attractive potential structural materials due to their high strength, particularly at elevated temperatures $[19,23]$. These alloys can be used as metallic matrix of very high strength Al-based composites. In an early work Galano et al. [24] milled a nanoquasicrystalline Al-based alloy powder with 8.5 vol.\% of $\gamma-\mathrm{Al}_{2} \mathrm{O}_{3}$ nanoparticles. Homogeneous alumina distribution on a nanoquasicrystalline matrix nanocomposite with high hardness value and minor quasicrystalline phase decomposition was obtained. In this work the ball milling process and the effects of processing parameters are investigated to produce a nanocomposite consisting of 12.9 vol.\% $\quad \gamma-\mathrm{Al}_{2} \mathrm{O}_{3} \quad(20-50 \mathrm{~nm})$ distributed in a nanoquasicrystalline Al-Fe-Cr-Ti matrix. The effects of milling speed on the nano-size $\gamma-\mathrm{Al}_{2} \mathrm{O}_{3}$ 
particles distribution in a nanoquasicrystalline Al-based matrix, the microstructure evolution and the hardness were investigated.

\section{Experimental Methods}

10 grams of gas atomized powder of the $\mathrm{Al}_{93} \mathrm{Fe}_{3} \mathrm{Cr}_{2} \mathrm{Ti}_{2}$ (at \%) nanoquasicrystalline alloy (A) with $25-50 \mu \mathrm{m}$ powder size range and 12.9 vol. $\% \gamma-\mathrm{Al}_{2} \mathrm{O}_{3}$ powder with particle size range of 20-50 nm were premixed in a Tubular mixer for 10 minutes. $100 \mathrm{~g}$ stainless steel balls of 10 $\mathrm{mm}$ in diameter and the mixed powder were loaded into a $250 \mathrm{ml}$ stainless steel vessel. This was done in an Argon filled glovebox. A Fritsch Mono Mill Pulverisette 6 Classic was used to process three batches of mixed powder with various milling speed from 200 rotates per minute (rpm) to $250 \mathrm{rpm}$. Twenty minutes pause was applied after each hour of milling to release the heat. For each powder batch, 0.5 grams was taken out after every 5 hours of milling until 30 hours. One batch of pure nanoquasicrystalline alloy powder was also milled with $250 \mathrm{rpm}$ under the same milling conditions that the composite powders for comparison. The milling speed and the corresponding batch number are shown in Table 1. As shown, the milled powder samples are referred to as $\mathrm{A} a \_b$ or $\mathrm{C} a \_b$, where $\mathrm{A}$ represents the nanoquasicrystalline alloy powder, and $\mathrm{C}$ the nanoquasicrystalline alloy plus alumina composites powders. The index $a$ stands for the milling speed (rpm) and the index $b$ for the milling hours, respectively.

\begin{tabular}{cc}
\hline Powder batch & Milling speed (rpm) \\
\hline A250 & 250 \\
C200 & 200 \\
C $250 / 200$ & 250 for the $1^{\text {st }} 5$ hours, and 200 afterwards \\
C250 & 250 \\
\hline Table 1: Ball milled powder batches and their milling speed
\end{tabular}

X-ray diffractograms were obtained with a Bruker D5000 $\theta-2 \theta$ diffractometer with $0.15418 \mathrm{~nm}$ wavelength $\mathrm{Cu}-\mathrm{K} \alpha$ radiation at $40 \mathrm{kV}$ and $40 \mathrm{~mA}$, with scan conditions of $2 \theta$ range of $20-100^{\circ}$, a step size of $0.02^{\circ}$ and a scan rate of $0.003^{\circ}$ s. Crystallite sizes and the strain of ball milled powder were estimated by the Williamson-Hall plot method [25]. A FEI 200 focus ion beam (FIB) was used for milling the oxide layer away to observe the alumina distribution in the milled powders. The lift-out transmission electron microscope (TEM) samples with thickness ranging from 60-130 nm were prepared with the FIB apparatus. The crystallite sizes were measured on bright field TEM images taken in a Jeol 2100 TEM. 
Vickers hardness (HV) was measured using a Wolpert hardness microindenter with 10 gramsforce load and $15 \mathrm{~s}$ of dwelling time. Powder samples were mounted in conductive Bakelite and polished until a metallographic quality surface. Vickers hardness was measured following the recommendations in the ASTM E384-16 standard [26]. Only powder particles with large circular surface in the mounted samples were measured with only one microindentation per powder particle. This allows meeting the recommended conditions of minimum thickness and the minimum distance from the centre of the indentation to the particle surface as 1.5 and 2.5 times of the indentation's diagonal, respectively. The Vickers hardness was calculated using the average value of the two diagonals of each microindentation and applying the corresponding formula for HV [26] , as in equation (1):

$$
\mathrm{HV}=1854.4 \frac{\mathrm{P}}{d^{2}}
$$

Where, $\mathrm{P}$ is the load in gf; $d$ is the average diagonal length value in $\mu \mathrm{m}$. For each milled powder sample, 20 symmetric indentations were used to ensure the accuracy of the Vickers hardness values.

\section{Results}

\subsection{Alumina distribution in the ball milled powder}

The FIB images of the milled powder produced at 200 and $250 \mathrm{rpm}$ are shown in Figure 1. For the C200 batch after 10 hours of milling (C200_10), the alumina appears in bands within the matrix, as shown in Figure 1 (a). Probably this is because the $\gamma-\mathrm{Al}_{2} \mathrm{O}_{3}$ particles that initially were stuck on the nanoquasicrystalline powder surface had been trapped inside when the quasicrystalline powder was cold welded together during the milling process. After 20 hours of milling (C200_20) the alumina distributes more homogeneously, as shown in Figure 1 (b). The progress towards to an alumina homogeneous distribution can be explained due to repeated cold-welding and fracturing cycles during the milling process [27]. The alumina distribution in the C250 batch powder follows a similar trend but more homogeneously than the C200 batch. In the C250_10 sample the alumina is distributed in the nanoquasicrystalline matrix forming thin bands with higher homogeneity than in the C200_10, (compare Figures 1 (a) and (c)). In the C250_20 sample the alumina seems quite homogeneously distributed (Figure 1 (d)) when compared with the C200_20 sample (Figure 1 (b)). The higher milling speed produces more 
collisions per unit volume of the powder leading to a more homogenous distribution for the same milling time.

\section{Figure 1: FIB images of $\mathrm{C} 200$ and $\mathrm{C} 250$ milled powders with 10 and 20 hours milling time}

\subsection{Phases present in the ball milled powder}

The X-ray diffractograms of the A250, C250 and C200 batches of powder are shown in Figure 2. Peaks at $2 \theta$ angles of $22.5,40.9,43.1,73.1$ degrees were indexed as corresponding to the icosahedral quasicrystalline phase using the Cahn's notation [28]. The peaks' intensity of the icosahedral quasicrystalline phase decreases with the milling time, which indicates a possible decomposition and/or a high distortion of the quasicrystalline phase structure by the ball collisions during the milling process. Only one small peak of the $\gamma-\mathrm{Al}_{2} \mathrm{O}_{3}$ was observed, the $\gamma(440)$ peak, identified in the composite powders. This could be due to a combination of low volume fraction and the nano-size particles of the $\gamma-\mathrm{Al}_{2} \mathrm{O}_{3}$ in the nanocomposites powder, which produces broad and low intensity diffraction peaks, as it was observed in a previous work [24]. The quasicrystal and the $\alpha$-Al peaks show broadenings with the milling time, which can be related with collisions and the fracturing process that reduce the $\mathrm{Al}$ crystallite size and distorts the $\mathrm{Al}$ and quasicrystal lattices.

Figure 2: The X-ray diffractograms of the milled powder samples

The icosahedral quasicrystalline phase and the $\gamma-\mathrm{Al}_{2} \mathrm{O}_{3}$ particles were also observed in the TEM analysis, as can be seen in the bright field TEM images from C200_10 and C250/200_10 samples in Figure 3 (a) and (b), respectively. The particle (1) is an icosahedral quasicrystal phase characterised by the convergent beam electron diffraction patterns from the mirror zone axis. The particle (3) is an icosahedral quasicrystal according to the fivefold diffraction pattern with quasiperiodic order. The particles (2) and (4) would correspond to $\gamma-\mathrm{Al}_{2} \mathrm{O}_{3}$ particles according to the EDX analysis showed in the inset in Figure 3. Particle (4) has higher aluminium atom percentage, probably because the EDX detector received information from the aluminium matrix. 


\section{Figure 3: Bright field TEM image of the (a) C200_10 (b) C250/200_10 samples; with insets of electron diffraction patterns of icosahedral quasicrystalline particles (particles}

1 and 3) and EDX results from alumina particles (particles 2 and 4).

\subsection{The Al crystallite size, the strain and the hardness}

The average $\mathrm{Al}$ crystallite size and the strain values of the ball milled powders were estimated through the Williamson-Hall plot method and summarised in Figure 4. Only powder samples of the C200 batch with milling time equal or higher than 20 hours, and samples of the C250/200 and C250 batches with milling time equal or higher than 10 hours were used for this estimation since Williamson-Hall plot produces large errors for Al crystallite sizes larger than $100 \mathrm{~nm}$ [24]. The Al crystallite sizes of the C250/200_5 and C250_5 samples were measured instead by drawing two pairs of parallel vertical and horizontal lines on each crystallite in the TEM images. The average distance between the vertical lines and the horizontal lines measured on at least $30 \mathrm{Al}$ crystallites was taken as the average $\mathrm{Al}$ crystallite size.

The average Al crystallite size of the milled powder decreases with milling time and speed, as shown in Figure 4. For example, for the C200 batch the Al crystallite size decreases from 99 $\mathrm{nm}$ to $30 \mathrm{~nm}$ from 20 to 30 hours of milling. In the C250 batch the crystallite size decreases from $130 \mathrm{~nm}$ to $14 \mathrm{~nm}$ from 5 to 30 hours of milling. It is observed that for the same milling time, samples produced with higher milling speed have smaller average Al crystallite size. The strain values of all milled powder batches do not show a clear trend. Most of the values lay between $1.0 \%$ and $1.5 \%$.

The Vickers hardness of the milled powder is also shown in Figure 4. C200 batch samples with milling time lower than 20 hours had an inhomogeneous microstructure therefore Vickers hardness tests were not performed on these samples with very inhomogeneous microstructure. Before milling the Vickers hardness of the nanoquasicrystalline alloy powder was $132 \pm 10$ $\mathrm{HV}_{10 \mathrm{~g}}$. The hardness values of all the nanocomposite samples ( $\mathrm{C}$ batches) increases with milling time and milling speed. The highest hardness values were observed for the $\mathrm{C} 250 \mathrm{batch}$ samples. These values increased from $407 \pm 59$ to $638 \pm 44 \mathrm{HV}_{10 \mathrm{~g}}$ from 5 to 30 hours of milling. The C250 nanocomposite batch showed higher hardness values than the A250 nanoquasicrystalline alloy batch. 


\section{Figure 4: The Al crystallite size, the Al crystallite strain and the Vickers hardness values of the ball milled powders against the milling time.}

\section{Discussion}

The hardness value $\left(\mathrm{HV}_{A 0}\right)$ measured on the unmilled nanoquasicrystalline alloy powder includes the contribution of all the strengthening mechanisms related to the nanoquasicrystalline alloy microstructure features. Considering that the volume fraction and the nano-size of quasicrystal/intermetallic precipitates embedded in the Al phase matrix (nanoquasicrystalline $\mathrm{Al}$ alloy) do not change during the ball milling process, the strengthening contribution by the Orowan's mechanism will remain constant with the milling time. In high strength alloys in which the particle and grain boundaries mechanisms are the main strengthening mechanisms, the solid solution represents a minor fraction contribution $(<5 \%)$ and the change in hardness during the milling process due to solid solution changes is even much lower [29, 30]. The dislocation-dislocation interaction strengthening mechanism is related with the dislocations density and therefore with the strain [31]. Figure 4 shows strain is lower than $1.5 \%$ and does not follow a clear trend, which suggests this strengthening mechanism does not contribute further to the hardness change with the milling time. From Figure 4 it is also observed that the $\mathrm{Al}$ crystallite size strongly decreases while the Vickers hardness increases with the milling time. Finally, it is reasonable to consider that the "change" in hardness values with the milling time is related mainly to the $\mathrm{Al}$ crystallite size refining. This suggests that the "increasing" of the materials strength should be related to the grain boundaries strengthening mechanism $[32,33]$.

The main hardening contributions to the nanoquasicrystalline alloy are the related to the Orowan's mechanism due to the $\sim 45$ vol. $\%$ of quasicrystals/intermetallic nano-size particles and to the grain boundaries (Hall-Petch) mechanism with an Al grain size of $\mathrm{d}_{0} \sim 1 \mu \mathrm{m}[19$, 23]. Then, during the ball milling process, when the Al crystallites are heavily refined, the "change" of the hardness of the nanoquasicrystalline alloy (A250) will follow a Hall-Petch type relationship as a function of the $\mathrm{Al}$ crystallite size. A general expression of hardening as a consequence of the crystallite refining is normally written as:

$$
H=H_{0}+\frac{k}{d^{p}}
$$


Where $H$ is the hardening due to the crystallite size $(d), H_{0}$ is the lattice frictional stress, $k$ is a constant known as "locking parameter", which measures the relative hardening contribution of the grain boundaries [34], and $p$ is a constant exponent. This exponent was suggested as $p=$ 0.5 by the early works of Hall [32] and Petch [33]. Deviations of this value have been theoretically proposed and experimentally found in the literature. Very early works by Mathewson in 1919 and Bragg in 1942 postulate that strength due to the crystallite size is proportional to $d^{-0.25}$ and $d^{-1}$, respectively [35,36]. Theoretical estimations in the literature for the $p$ value also suggested values as: 1.0, 0.5, 0.33, and 0.25. Each of these values for $p$ is based on different mechanisms and/or models for dislocation-grain boundary interactions. For example, the more common value, $p=0.5$, is normally related to dislocations pile up at the grain boundaries; and $p=0.25$ was also found by Conrad considering a dislocation forest hardening concept $[37,38]$. Several models considering different dislocation-grain boundaries interactions, crystallite size ranges, boundaries features as porosity and impurities, solute diffusivity, dislocation sources have been proposed leading to different $p$ values and even different complex equations as a function of the crystallite size [39]. The ball milling process introduces several physical changes in the Al lattice and grain boundaries that make it extremely difficult to build up a theoretical approach to propose an equation that accurately describes the hardening mechanism related to the crystallite refining experimentally observed. Thus, the experimental results obtained from the milled alloy and composite powder were fitted following the simple equation (2), finding an exponent $p=0.25$ for the best lineal correlation between measured $\mathrm{H}$ values and $\frac{1}{d^{p}}$, as can be seen in Figure 5 for the alloy powder (a) and the composite powder (b). The lineal correlation following a Hall-Petch type relationship suggests that during the milling process of the alloy and the composite the hardening is mainly controlled by the crystallite refining, as was deduced above. Therefore, it is reasonable to suggest that the "change" of hardness respect to the initial hardness of the unmilled powder can be represented by $\frac{k}{d^{p}}$. Finally, the hardness value of the milled alloy powder after $\mathrm{x}$ hours of milling, $H_{A x}$, can be estimated using equation (3):

$$
H_{A x}=\left(H_{A 0}-\frac{k A}{d_{0}^{\frac{1}{4}}}\right)+\frac{k A}{d_{x}^{\frac{1}{4}}}
$$

Where $k_{A}$ is the "locking parameter" for the alloy, and $H_{A 0}$ is the microhardness value of the unmilled nanoquasicrystalline Al-Fe-Cr-Ti alloy powder (measured as $132 \pm 10 \mathrm{HV}_{10 \mathrm{~g}}$ ) that includes the Al lattice frictional stress, the effects of solutes in the Al solid solution, 
quasicrystal/intermetallic particles hardening, grain boundaries hardening and other minor contributions. Thus, in order to count only the constant hardening contributions of the microstructure of the milled powders, the grain boundaries contribution for the initial Al grain size $\left(\mathrm{d}_{0}\right)$ must be subtracted as: $\frac{k A}{d_{0}^{\frac{1}{4}}}$ from $H_{A 0} \cdot d_{x}$ is the Al crystallite size after $\mathrm{x}$ hours of milling, which is the main observed microstructural feature that changes during the ball milling process in the nanoquasicrystalline alloy powder. For the unmilled alloy powder, when $d_{x}=d_{0}$ the equation (3) provides a hardness value equal to the measured hardness of the unmilled alloy powder, $H_{\mathrm{A} 0}$.

For the composite powders, because of the addition of the nano $\gamma-\mathrm{Al}_{2} \mathrm{O}_{3}$ particles, other strengthening contributions must be considered. Numerous theoretical models have been developed to correlate the mechanical behaviour of metal matrix composites with their microstructural characteristics [40-46]. These models might be grouped into three general categories: (1) load transfer models, (2) matrix strengthening models and (3) hybrid models. (1): the load transfer models were developed on the basis that the hard, relatively undeformable reinforcements, may carry more load than the relatively soft matrix [40-42]. In this group is included the simplest and well know rule of mixtures (ROM) [42], which is characterized for a mathematical expression which gives the homogeneous property of a heterogeneous materials in terms of the properties, quantity and arrangement of its constituents. This model weights the volume average of the component properties in isolation without considering any interaction between reinforcement and matrix. See equation (4) as applicable for the composite's hardness:

$$
H_{C}=H_{A}(1-f)+H_{r} f
$$

where $H_{C}, H_{A}, H_{r}$ are the hardness values for the composite, the matrix alloy and the reinforcement, respectively. $f$ is the volume fraction of reinforcements.

(2): In the matrix strengthening models, the strengthening effect has been attributed to various microstructural changes experienced by the matrix as a result of the presence of reinforcement particulates [43]. For example, the stress increment resulting from the difference of the thermal expansion coefficient of matrix and reinforcement when the nanomaterial process involves temperature changes; an increase in strengthening by Orowan's mechanism when the reinforcements are located inside of the matrix grains.

(3): other authors proposed hybrid models that combine both approaches of load transfer and effects of the matrix microstructural changes due to the reinforcements addition [44-46]. 
In the present work, we adopt a hybrid model to evaluate the hardness change with the ball milling time of a composite powder using the equation (5):

$$
H_{C x}=\left[\left(H_{A 0}-\frac{k c}{d_{0}^{\frac{1}{4}}}\right)+\frac{k c}{d_{x}^{\frac{1}{4}}}\right](1-f)+H_{r} f \quad \text {------- } \quad \text { Equation (5) }
$$

where $H_{C x}$ is the hardness of the nanocomposite after $x$ hours of milling, $k_{C}$ is the "locking parameter" for the composite, $f$ is the volume fraction of the $\gamma-\mathrm{Al}_{2} \mathrm{O}_{3}$ reinforcement $(12.9 \%)$, and $H_{r}$ is the hardness value of the reinforcement $\left(\gamma-\mathrm{Al}_{2} \mathrm{O}_{3}\right.$ with an average value taken from literature as $\left.730 \mathrm{Kg} / \mathrm{mm}^{2}\right)$ [11-13]. When no reinforcement is added to the powder alloy $(f=0)$ equation (5) becomes equation (3) giving the hardness values for the milled alloy powders. The equation (5) predict a theoretical hardness value of the unmilled composite of $H_{C 0}=209$ $\mathrm{Kg} / \mathrm{mm}^{2}$ by the application of the simple rule of mixtures.

It is worth mentioning that in composite systems where the reinforcement particle is much harder than the matrix or the volume fraction of the reinforcement is low, the ROM as in equation (4) may not predict the actual hardness of the composite due high plastic deformation around the hard particles that produce a zone of high dislocations density [42]. For example, for the $\mathrm{Ag}-\mathrm{Al}_{2} \mathrm{O}_{3}$ composites, with a very soft $\mathrm{Ag}$ matrix, the experimental values of the hardness are almost the same up to 50 vol.\% $\mathrm{Al}_{2} \mathrm{O}_{3}$ [47]. However, in the literature, for mechanical milled aluminium composites with about 10-20\% volume fraction of ceramic reinforcement particles, the experimental results match the value estimated with the rule of mixtures [14, 48]. The equation (5) combines the equation (3) and the rule of mixtures (equation (4)). The mechanical milling and alumina affects the microstructure of the nanoquasicrystalline $\mathrm{Al}$ alloy matrix of the composite. As discussed above, the main observed microstructural features that change with the milling time in the composite are the refining of the $\mathrm{Al}$ crystallites in the matrix and a continue homogenisation of alumina distribution. The effect on the alloy matrix introduced by the $\gamma-\mathrm{Al}_{2} \mathrm{O}_{3}$ reinforcement is represented in the equation (5) by the term: $\frac{k c}{d_{x}^{p}}(1-f)$ were $f$ considers the quantity of reinforcement in the composite, $d_{x}$ the size of the crystallite size in the matrix alloy, and the exponent $p=0.25$, which in this work was obtained by fitting the hardness and $\mathrm{Al}$ crystallite size measured on the milled powders. This $p$ value matches with the early model proposed by Conrad and Hirth [37, 38] that consider a dislocation forest hardening concept. Moreover, the parameter $k_{C}$ that was fitted for the composite powder is different than the one for the alloy powder $\left(k_{A}\right)$. The "blocking parameter", $k$, is associated with the stress required to extend dislocations activity 
into nearby grains and is very sensitive to the composition of the alloy and composites $[34,50$ 53]. For example, when adding $4 \mathrm{wt} . \%$ of $\mathrm{Cu}$ to the pure $\mathrm{Al}$, the $k$ value resulted more than 2 times of the one corresponding to the nanocrystalline pure $\mathrm{Al}[50,51]$. In the present work, considering that some $\gamma-\mathrm{Al}_{2} \mathrm{O}_{3}$ nanoparticles would be distributed at the $\mathrm{Al}$ grain boundaries in the alloy matrix, the hardening behaviour in the alloy and in the composite powders would be different, which lead to different $k$ values that measures the properties of the grain boundaries as a sink and source of dislocations [49].

In Figure 5 (a) the slope of the linear fitting for the milled alloy powder resulted as $k_{A}=$ $1463 \pm 183 \mathrm{~kg} / \mathrm{mm}^{2} \cdot \mathrm{nm}^{1 / 4}\left(2551 \pm 319 \mathrm{MPa} \cdot \mu \mathrm{m}^{1 / 4}\right)$. The $k_{C}$ value for the milled composite powders was also fitted linearly as can be observed in Figure 5 (b) taken the data for all the composite powder batches, finding a value of the slope as: $k_{C}(1-f)=938 \pm 122 \mathrm{~kg} / \mathrm{mm}^{2}$. $\mathrm{nm}^{1 / 4}$. Thus, $k_{C}=1077 \pm 140 \mathrm{~kg} / \mathrm{mm}^{2} \cdot \mathrm{nm}^{1 / 4}\left(1878 \pm 244 \mathrm{MPa} \cdot \mu \mathrm{m}^{1 / 4}\right)$, which is lower than the obtained for the milled alloy powders showing the effect of the $\gamma-\mathrm{Al}_{2} \mathrm{O}_{3}$ nanoparticles on the $\mathrm{Al}$ grain boundaries of the alloy matrix.

The values estimated from the linear fitting for the alloy data have larger errors, probably due to the limited number of samples in comparison with the data obtained for the composite powders. The data for the alloy and the composite were statistically evaluated by means of the Chauvenet's criterion [54] and only one data for the alloy has not been taken into account in the fitting; the one corresponded to the A250_15 sample (crossed in Figure 5 (a)).

\section{Figure 5: The linear fit model for the (a) milled alloy and (b) nanocomposite powders. The measured Vickers hardness against $d^{-0.25}$ (d: Al crystallite size)}

The application of the equations (3) and (5) to predict the hardness value of the milled nanoquasicrystalline $\mathrm{Al}-\mathrm{Fe}-\mathrm{Cr}-\mathrm{Ti}$ alloy and for it composites containing $12.9 \mathrm{vol} . \% \gamma-\mathrm{Al}_{2} \mathrm{O}_{3}$ (20-50 nm) powders provided hardness values slightly lower but inside the error of the measured hardness values. The estimated hardness powders milled for 30 hs present higher deviation $(\sim 15 \%)$, which can be explained because after 30 hs of milling some icosahedral quasicrystalline particles appear to be transformed which change the alloy matrix and as consequence the microstructural parameters in the equations should change too.

The hardness value obtained for the nanoquasicrystalline Al-Fe-Cr-Ti alloy matrix $/ \gamma-\mathrm{Al}_{2} \mathrm{O}_{3}$ particles nanocomposite powders are very high in comparison with the ones found in the 
literature, which are summarised in Table 2. This can be explained because of the large volume fraction ( 42-45\%) of the quasicrystal nanoparticles embedded in fcc-Al phase, obtained by rapid solidification, produces a high strength alloy which can transfer load to the hard $\gamma-\mathrm{Al}_{2} \mathrm{O}_{3}$ reinforcements more efficiently than softer Al-based commercial alloys.

\begin{tabular}{|c|c|c|c|}
\hline Composite & Al Crystallite size & Hardness & Reference \\
\hline $\begin{array}{l}\mathrm{NQX}(25-50 \mu \mathrm{m})+12.9 \text { vol. } \% \gamma-\mathrm{Al}_{2} \mathrm{O}_{3} \\
(20-50 \mathrm{~nm})\end{array}$ & $14 \mathrm{~nm}$ & $638 \pm 44 \mathrm{HV}_{10 \mathrm{~g}}$ & This work \\
\hline $\begin{array}{l}\mathrm{NQX}(25-50 \mu \mathrm{m})+8.5 \mathrm{vol} . \% \gamma-\mathrm{Al}_{2} \mathrm{O}_{3} \\
(20-50 \mathrm{~nm})\end{array}$ & $33 \mathrm{~nm}$ & $542 \pm 9 \mathrm{HV}_{10 \mathrm{~g}}$ & {$[24]$} \\
\hline $\begin{array}{l}\text { EN AW-2017 Al alloy }(100 \mu \mathrm{m})+ \\
15 \text { vol. } \% \mathrm{Al}_{2} \mathrm{O}_{3}(22 \mu \mathrm{m})\end{array}$ & $49 \mathrm{~nm}$ & $329 \pm 26 \mathrm{HV}_{100 \mathrm{~g}}$ & {$[55]$} \\
\hline $\mathrm{Al}(325 \mathrm{mesh})+10 \mathrm{vol} . \% \mathrm{Al}_{2} \mathrm{O}_{3}(4 \mathrm{~nm})$ & $90 \mathrm{~nm}$ & $166 \pm 4 \mathrm{HV}_{50 \mathrm{~g}}$ & {$[43]$} \\
\hline
\end{tabular}

Table 2: The Al crystallite size and hardness values of ball milled composite powders in literature. NQX is the abbreviation of the nanoquasicrystalline $\mathrm{Al}$ alloy

\section{Conclusion}

The nanoquasicrystalline $\mathrm{Al}_{93} \mathrm{Fe}_{3} \mathrm{Cr}_{2} \mathrm{Ti}_{2}$ alloy based nanocomposites powder containing 12.9 vol. $\% \gamma-\mathrm{Al}_{2} \mathrm{O}_{3}(20-50 \mathrm{~nm})$ has been produced by mechanical milling process. Homogeneous $\gamma-$ $\mathrm{Al}_{2} \mathrm{O}_{3}$ distribution and very high Vickers hardness is obtained after 20 hours of milling at 200 rpm or for 10 hours of milling at $250 \mathrm{rpm}$. The metastable quasicrystalline phase has remained after 30 hours of milling even at $250 \mathrm{rpm}$.

As the milling speed increases, collisions per unit volume of the powder increase; thus distributes the alumina particles, refines the $\mathrm{Al}$ crystallite size and increases the hardness of the composites more efficiently.

The hardness of the nanoquasicrystalline $\mathrm{Al}$ alloy powder is mainly controlled by the refining of the Al crystallite size during the milling process. Thus the hardness change of the milled nanoquasicrystalline $\mathrm{Al}$ alloy powder can be estimated by a simple Hall-Petch type relationship with an exponent of 0.25 in accordance of early models based on dislocation forest hardening concept. 
The hardness change of the ball milled nanocomposite powder can be estimated by a hybrid model that combines a Hall-Petch type relationship with an exponent of 0.25 and the rule of mixtures.

The addition of 12.9 vol. $\% \gamma-\mathrm{Al}_{2} \mathrm{O}_{3}(20-50 \mathrm{~nm})$ particles to the nanoquasicrystalline $\mathrm{Al}_{93} \mathrm{Fe}_{3} \mathrm{Cr}_{2} \mathrm{Ti}_{2}$ alloy powder processed by ball milling with a ball to powder ratio of 10 , at 250 rpm during $30 \mathrm{hs}$ allows to obtain an homogeneous nanocomposite powder with 4.8 times higher hardness $\left(\mathrm{HV}_{10 \mathrm{~g}}=638\right)$ than that of the nanoquasicrystalline $\mathrm{Al}$ alloy matrix $\left(\mathrm{HV}_{10 \mathrm{~g}}=\right.$ 132).

\section{Acknowledgement}

The authors thank Alpoco Ltd. for their support to the project and Philip Holdway for X-ray diffractorgams. Prof. M. Galano thanks the RAEng for the EP/G05794X/1 award that partially supported this work. This work was also partially supported by the cooperation project PICTOxford 2831, Argentina, and the UBACYT 20020130100663 project.

\section{Reference}

[1] A. Kelly, Composites in context, Composites Science and Technology, 23 (1985) 171-199. [2] Y.C. Kang, S.L.I. Chan, Tensile properties of nanometric $\mathrm{Al}_{2} \mathrm{O}_{3}$ particulate-reinforced aluminum matrix composites, Materials Chemistry and Physics, 85 (2004) 438-443.

[3] A. Knowles, X. Jiang, M. Galano, F. Audebert, Microstructure and mechanical properties of $6061 \mathrm{Al}$ alloy based composites with SiC nanoparticles, Journal of Alloys and Compounds, 615 (2014) S401-S405.

[4] W. Gu, Bulk Al/SiC nanocomposite prepared by ball milling and hot pressing method, Transactions of Nonferrous Metals Society of China, 16 (2006) s398-s401.

[5] J.C. Lee, J.Y. Byun, S.B. Park, H. Lee, Prediction of Si contents to suppress the formation of $\mathrm{Al}_{4} \mathrm{C}_{3}$ in the $\mathrm{SiCp} / \mathrm{Al}$ composite, Acta Materialia, 46 (1998) 1771-1780.

[6] B. Prabhu, C. Suryanarayana, L. An, R. Vaidyanathan, Synthesis and characterization of high volume fraction $\mathrm{Al}-\mathrm{Al}_{2} \mathrm{O}_{3}$ nanocomposite powders by high-energy milling, Materials Science and Engineering A, 425 (2006) 192-200. 
[7] A.I. Osman, J.K. Abu-Dahrieh, D.W. Rooney, S.A. Halawy, M.A. Mohamed, A. Abdelkader, Effect of precursor on the performance of alumina for the dehydration of methanol to dimethyl ether, Applied Catalysis B: Environmental, 127 (2012) 307-315.

[8] JCPDS reference no. 00-010-0425.

[9] Y. Rozita, R. Brydson, A. Scott, An investigation of commercial gamma- $\mathrm{Al}_{2} \mathrm{O}_{3}$ nanoparticles, in: Journal of Physics: Conference Series, IOP Publishing, 2010, pp. 012096.

[10] Y. Wang, C. Suryanarayana, L. An, Phase Transformation in Nanometer-Sized $\gamma$-Alumina by Mechanical Milling, Journal of the American Ceramic Society, 88 (2005) 780-783.

[11] T. Chou, T. Nieh, S. McAdams, G. Pharr, Microstructures and mechanical properties of thin films of aluminum oxide, Scripta Metallurgica et Materialia, 25 (1991) 2203-2208.

[12] R.S. Mishra, C.E. Lesher, A.K. Mukherjee, High-Pressure Sintering of Nanocrystalline rA12O3, Journal of the American Ceramic Society, 79 (1996) 2989-2992.

[13] M.R. Gallas, B. Hockey, A. Pechenik, G.J. Piermarini, Fabrication of Transparent $\gamma-\mathrm{Al}_{2} \mathrm{O}_{3}$ from Nanosize Particles, Journal of the American Ceramic Society, 77 (1994) 2107-2112.

[14] Y. Mazaheri, F. Karimzadeh, M.H. Enayati, Nanoindentation Study of $\mathrm{Al} 356-\mathrm{Al}_{2} \mathrm{O}_{3}$ Nanocomposite Prepared by Ball Milling, Materials Sciences and Applications, 1 (2010) 217222.

[15] M. Galano, F. Audebert, B. Cantor, I. Stone, Structural characterisation and stability of new nanoquasicrystalline Al-based alloys, Materials Science and Engineering A, 375-377 (2004) 1206-1211.

[16] M. Galano, F. Audebert, I.C. Stone, B. Cantor, Effect of Nb on nanoquasicrystalline Albased alloys, Philosophical Magazine Letters, 88 (2008) 269-278.

[17] M. Galano, F. Audebert, I.C. Stone, B. Cantor, Nanoquasicrystalline Al-Fe-Cr-based alloys. Part I: Phase transformations, Acta Materialia, 57 (2009) 5107-5119.

[18] A. Inoue, Amorphous, nanoquasicrystalline and nanocrystalline alloys in Al-based systems, Progress in Materials Science, 43 (1998) 365-520.

[19] F. Audebert, F. Prima, M. Galano, M. Tomut, P.J. Warren, I.C. Stone, B. Cantor, Bulk Amorphous, Nano-Crystalline and Nano-Quasicrystalline Alloys. Materials Transactions, JIM, 43 (2002) 2017-2025.

[20] M. Galano, F. Audebert, A. Garcia Escorial, I.C. Stone, B. Cantor, Nanoquasicrystalline Al-Fe-Cr-based alloys with high strength at elevated temperature, Journal of Alloys and Compounds, 495 (2010) 372-376. 
[21] F. Audebert, M. Galano, C.T. Rios, H. Kasama, M. Peres, C. Kiminami, W.J. Botta, C. Bolfarini, Nanoquasicrystalline $\mathrm{Al}-\mathrm{Fe}-\mathrm{Cr}-\mathrm{Nb}$ alloys produced by powder metallurgy, Journal of Alloys and Compounds, 577 (2013) 650-657.

[22] F. Audebert; Amorphous and Nanostructured Al-Fe and Al-Ni Based Alloys, in Properties and Applications of Nano-crystalline Alloys from Amorphous Precursors; Series: NATO Science Series II: Mathematics, Physics and Chemistry, Vol. 184, Eds. B. Idzikowski, P. Švec, M. Miglierini, Kluwer Acad. Publishers, Dordrecht, 2005, p.p. 301-312.

[23] M. Galano, F. Audebert, A. Garcia Escorial, I. Stone, B. Cantor, Nanoquasicrystalline AlFe-Cr-based alloys. Part II. Mechanical properties, Acta materialia, 57 (2009) 5120-5130.

[24] M. Galano, A. Marsh, F. Audebert, W. Xu, M. Ramundo, Nanoquasicrystalline Al-based matrix $/ \gamma-\mathrm{Al}_{2} \mathrm{O}_{3}$ nanocomposites, Journal of Alloys and Compounds, 643 (2015) S99-S106.

[25] G. Williamson, W. Hall, X-ray line broadening from filed aluminium and wolfram, Acta Metallurgica, 1 (1953) 22-31.

[26] ASTM, E384-16: Standard test method for microindentation hardness of materials, American Society for Testing Materials, ASTM International, USA (2016).

[27] J. Fogagnolo, F. Velasco, M. Robert, J. Torralba, Effect of mechanical alloying on the morphology, microstructure and properties of aluminium matrix composite powders, Materials Science and Engineering A, 342 (2003) 131-143.

[28] J.W. Cahn, D. Shechtman, D. Gratias, Indexing of icosahedral quasiperiodic crystals, Journal of Materials Research, 1 (1986) 13-26.

[29] G.P.M. Leyson, W.A. Curtin, L.G. Hector Jr, C.F. Woodward, Quantitative prediction of solute strengthening in aluminium alloys, Nature Materials, 9 (2010) 750-755.

[30] S. Pedrazzini, M. Galano, F. Audebert, D. Collins, F. Hofmann, B. Abbey, A. Korsunsky, M. Lieblich, A. Garcia Escorial, G. Smith, Strengthening mechanisms in an Al-Fe-Cr-Ti nanoquasicrystalline alloy and composites, Materials Science and Engineering A, 672 (2016) 175183.

[31] G. Williamson, R. Smallman, III. Dislocation densities in some annealed and cold-worked metals from measurements on the X-ray debye-scherrer spectrum, Philosophical Magazine, 1 (1956) 34-46.

[32] E. Hall, The deformation and ageing of mild steel: III discussion of results, Proceedings of the Physical Society. Section B, 64 (1951) 747-753.

[33] N. Petch, The cleavage strength of polycrystals, J. Iron Steel Inst., 174 (1953) 25-28.

[34] G.E. Dieter, D.J. Bacon, Mechanical metallurgy, McGraw-Hill New York, 1986.

[35] C.H. Mathewson, Discussion, Transaction TMS-AIME, 60, (1991) 451-455. 
[36] W. Bragg, A theory of the strength of metals, Nature, 149 (1942) 511-513.

[37] H. Conrad, Effect of grain size on the lower yield and flow stress of iron and steel, Acta Metallurgica, 11 (1963) 75-77.

[38] J.P. Hirth, The influence of grain boundaries on mechanical properties, Metallurgical Transactions, 3 (1972) 3047-3067.

[39] Z. Cordero, B. Knight, C. Schuh, Six decades of the Hall-Petch effect-a survey of grainsize strengthening studies on pure metals, International Materials Reviews, 61 (2016) 495-512. [40] J.D. Eshelby, The determination of the elastic field of an ellipsoidal inclusion, and related problems, in: Proceedings of the Royal Society of London A: Mathematical, Physical and Engineering Sciences, The Royal Society, 1957, pp. 376-396.

[41] V. Nardone, K. Prewo, On the strength of discontinuous silicon carbide reinforced aluminum composites, Scripta Metallurgica, 20 (1986) 43-48.

[42] H.S. Kim, On the rule of mixtures for the hardness of particle reinforced composites, Materials Science and Engineering A, 289 (2000) 30-33.

[43] D. Poirier, R.A. Drew, M.L. Trudeau, R. Gauvin, Fabrication and properties of mechanically milled alumina/aluminum nanocomposites, Materials Science and Engineering A, 527 (2010) 7605-7614.

[44] Y. Wu, E. Lavernia, Strengthening behavior of particulate reinforced MMCs, Scripta Metallurgica et Materialia, 27 (1992) 173-178.

[45] N. Ramakrishnan, An analytical study on strengthening of particulate reinforced metal matrix composites, Acta Materialia, 44 (1996) 69-77.

[46] S. Scudino, G. Liu, M. Sakaliyska, K. Surreddi, J. Eckert, Powder metallurgy of Al-based metal matrix composites reinforced with $\beta$-Al3Mg2 intermetallic particles: Analysis and modeling of mechanical properties, Acta Materialia, 57 (2009) 4529-4538.

[47] A.L. Greer, Partially or fully devitrified alloys for mechanical properties, Materials Science \& Engineering A, 304-306 (2001) 68-72.

[48] Y. Li, Y. Zhao, V. Ortalan, W. Liu, Z. Zhang, R. Vogt, N. Browning, E. Lavernia, J. Schoenung, Investigation of aluminum-based nanocomposites with ultra-high strength, Materials Science and Engineering A, 527 (2009) 305-316.

[49] J. Li, T. Ohmura, K. Tsuzaki, Evaluation of Grain Boundary Effect on Strength of Fe-C Low Alloy Martensitic Steels by Nanoindentation Technique, Materials Transactions, 46 (2005) 1301-1305. 
[50] T. Shanmugasundaram, M. Heilmaier, B. Murty, V.S. Sarma, On the Hall-Petch relationship in a nanostructured Al-Cu alloy, Materials Science and Engineering A, 527 (2010) 7821-7825.

[51] H. Choi, S. Lee, J. Park, D. Bae, Tensile behavior of bulk nanocrystalline aluminum synthesized by hot extrusion of ball-milled powders, Scripta Materialia, 59 (2008) 1123-1126. [52] R. Hayes, D. Witkin, F. Zhou, E. Lavernia, Deformation and activation volumes of cryomilled ultrafine-grained aluminum, Acta Materialia, 52 (2004) 4259-4271.

[53] D. Vojtěch, J. Verner, J. Šerák, F. Šimančík, M. Balog, J. Nagy, Properties of thermally stable PM Al-Cr based alloy, Materials Science and Engineering A, 458 (2007) 371-380.

[54] P.R. Bevington, D.K. Robinson, Data reduction and error analysis, McGraw-Hill, 2003.

[55] I. Ozdemir, S. Ahrens, S. Mücklich, B. Wielage, Nanocrystalline $\mathrm{Al}^{-} \mathrm{Al}_{2} \mathrm{O}_{3} \mathrm{p}$ and $\mathrm{SiCp}$ composites produced by high-energy ball milling, Journal of Materials Processing Technology, 205 (2008) 111-118. 


\section{Figures}
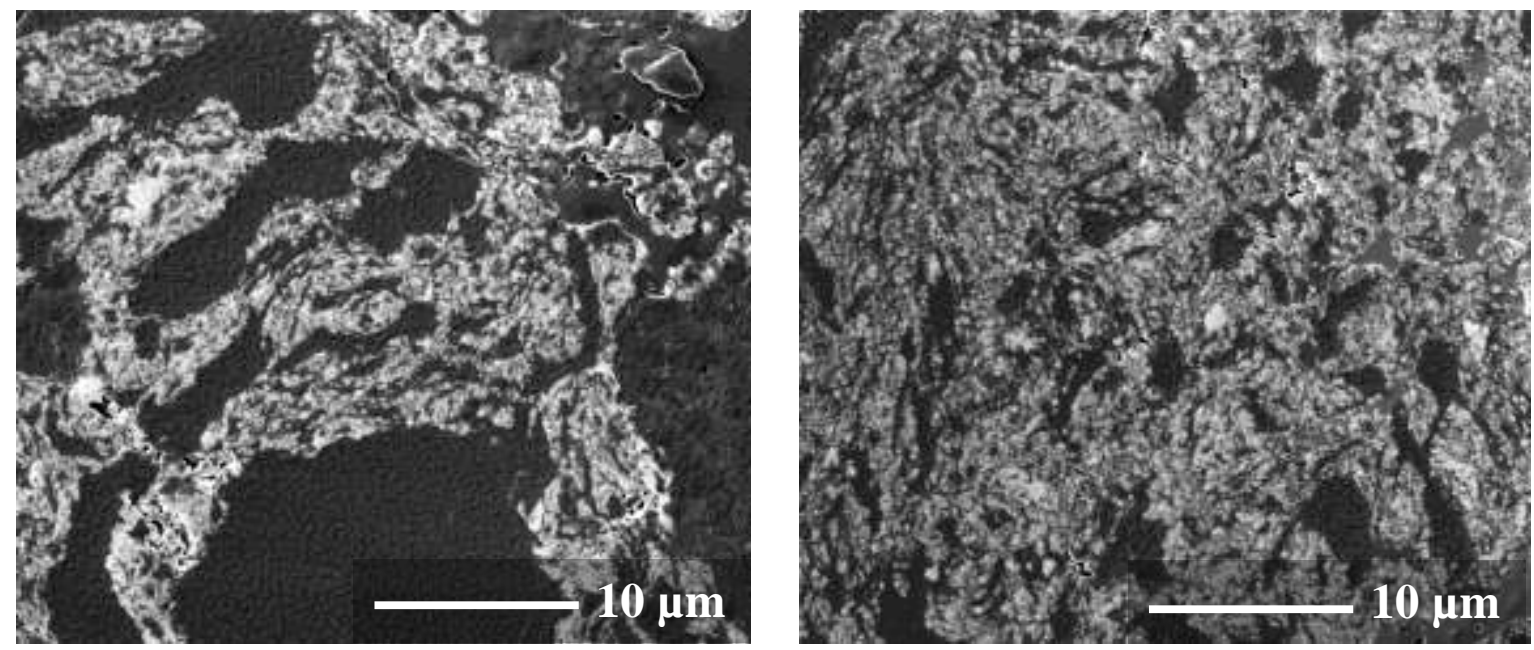

(a) C200_10

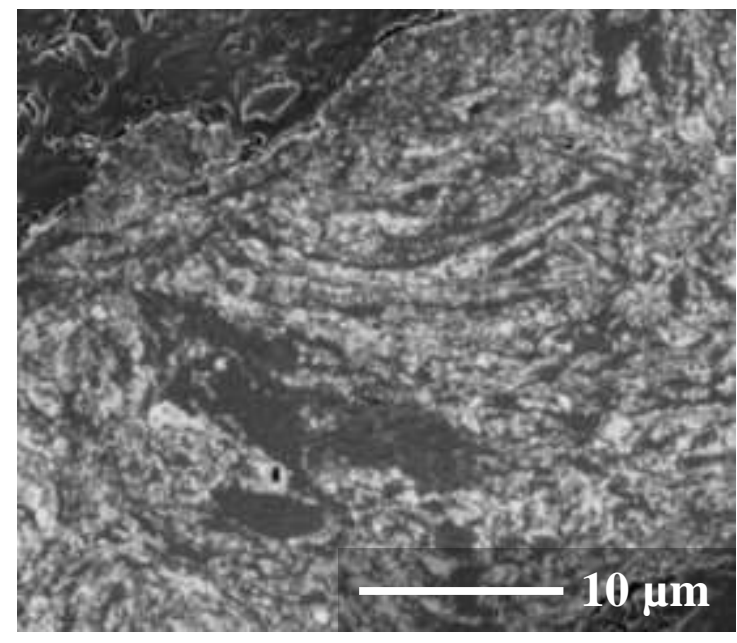

b) C200_20

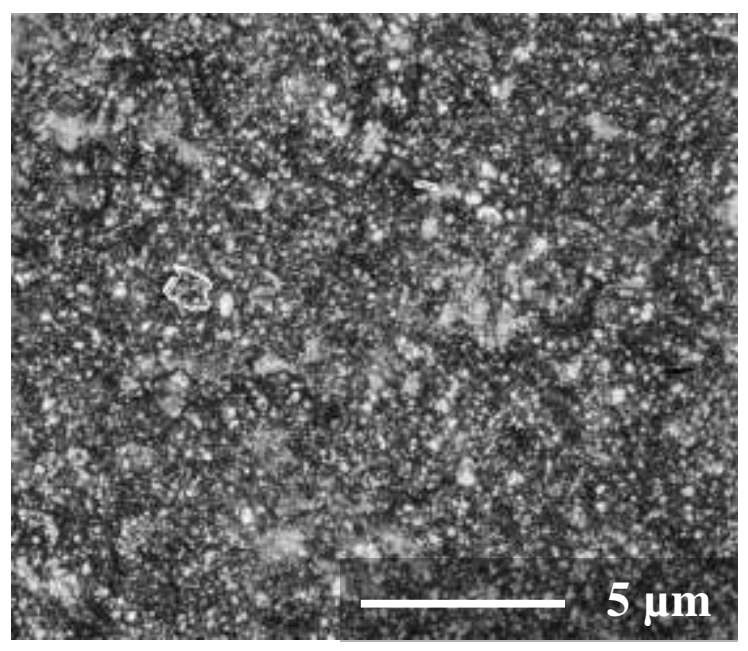

(c) C250_10

(d) C250_20

Figure 1: FIB images of $\mathrm{C200}$ and $\mathrm{C} 250$ milled powders with 10 and 20 hours milling time 


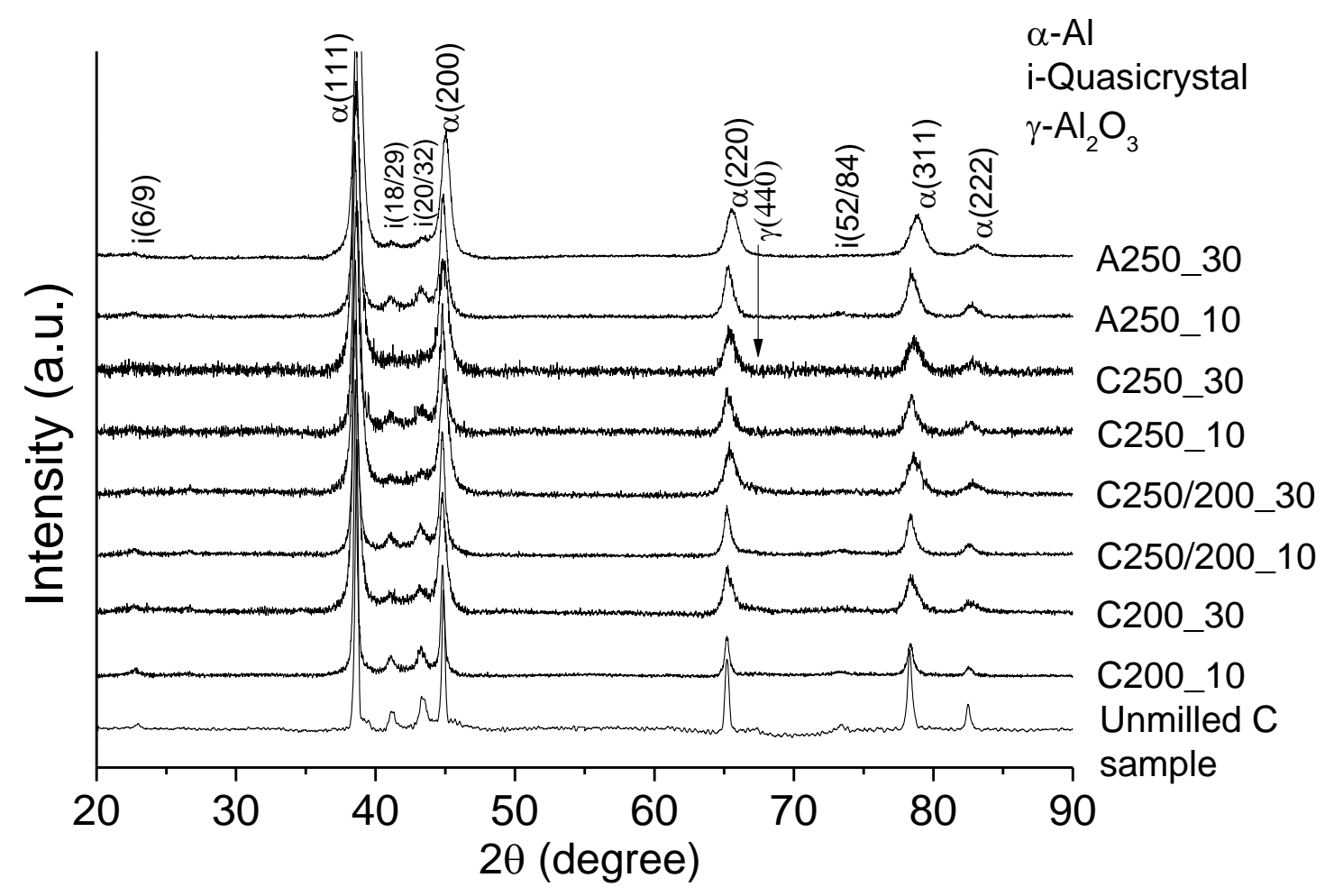

Figure 2: X-ray diffractograms of the milled powder samples

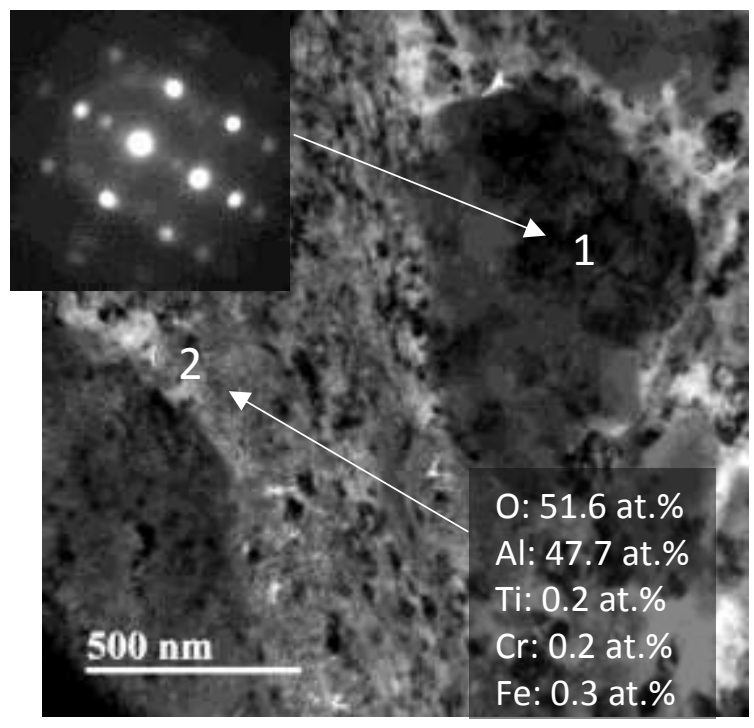

(a)

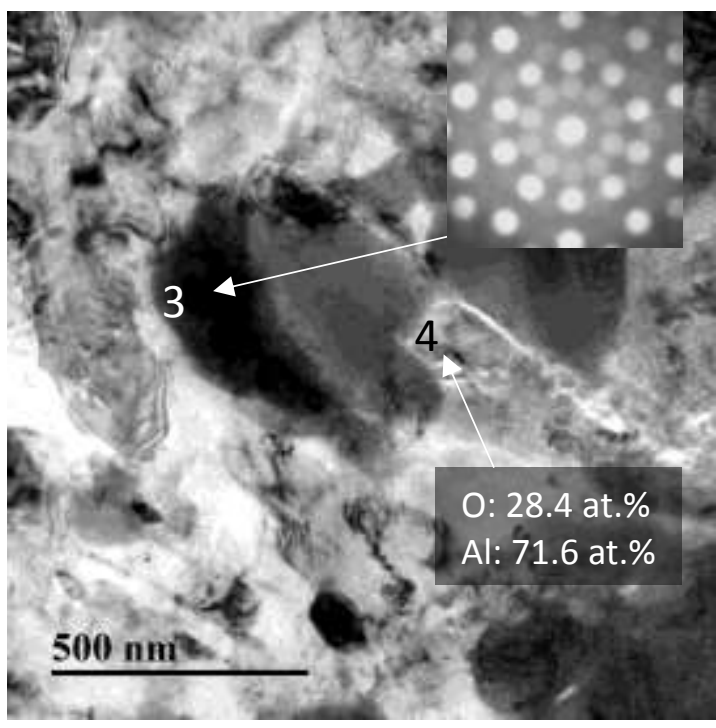

(b)

Figure 3: Bright field TEM image of the (a) C200_10 (b) C250/200_10 sample; with insets of electron diffraction patterns of quasicrystalline particles (particles 1 and 3) and EDX results from alumina particles (particles 2 and 4). 


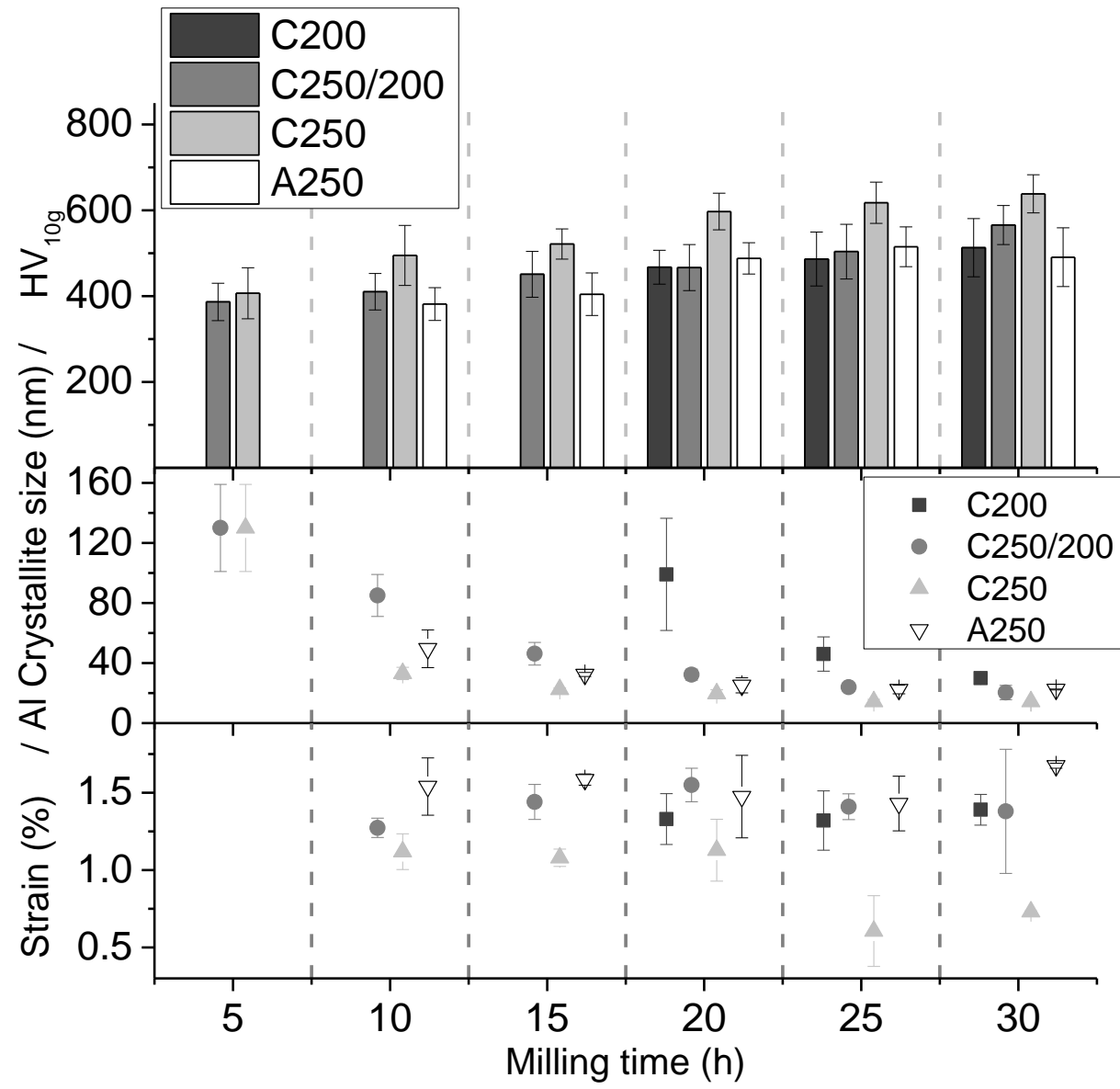

Figure 4: The Al crystallite size, the Al crystallite strain and the Vickers hardness values of the ball milled powders against the milling time. 


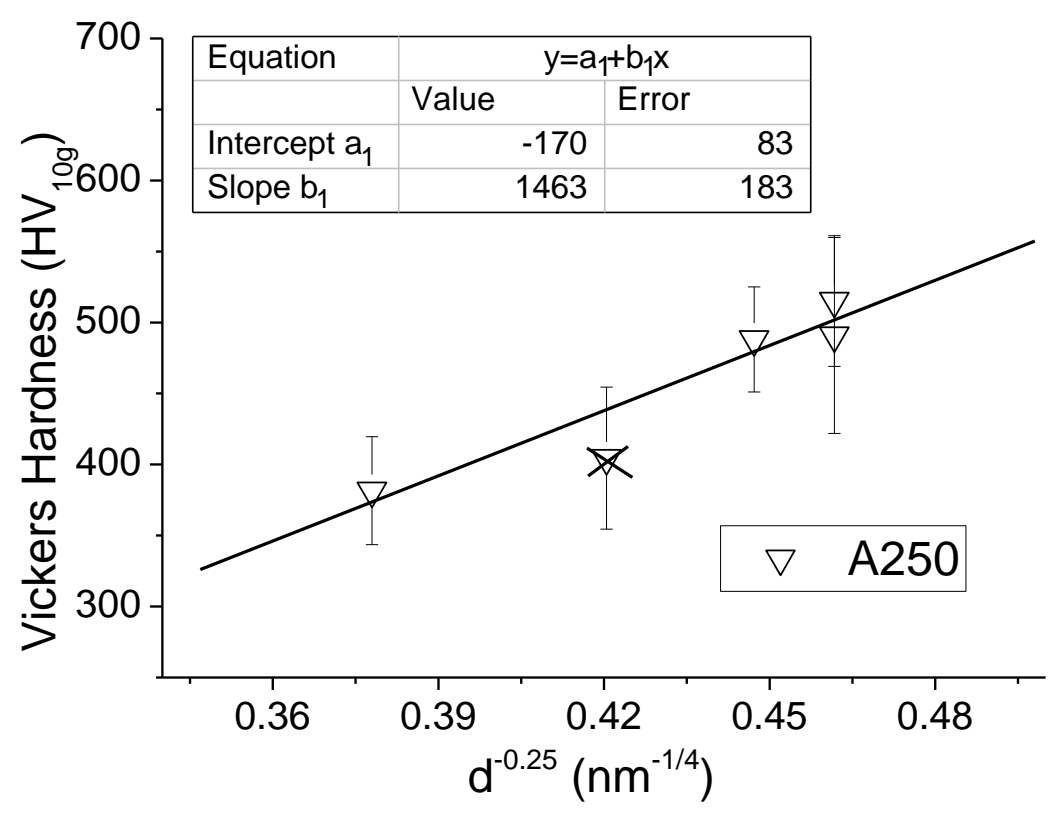

(a)

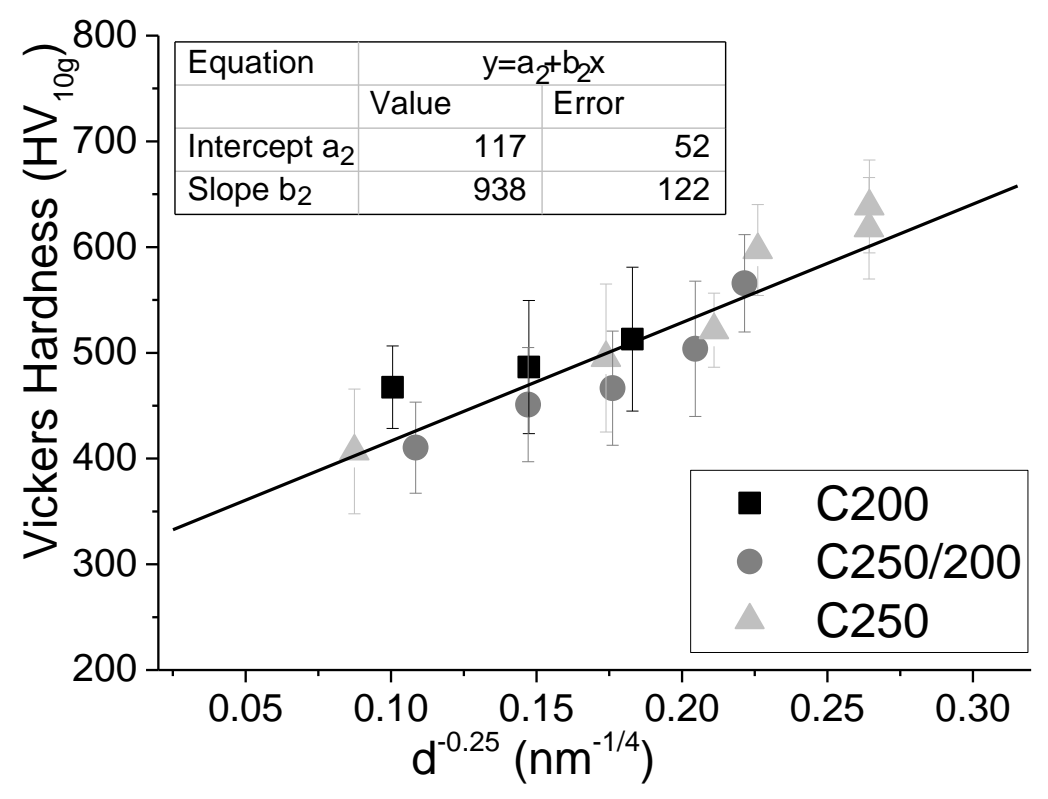

(b)

Figure 5: The linear fit model for the (a) milled alloy and (b) nanocomposite powders.

The measured Vickers hardness against $d^{-0.25}$ (d: Al crystallite size) 